qHBsAg kỹ thuật đơn giản, kết quả nhanh, chi phí thấp, tự động hóa $[6,8]$.

\section{KẾT LUẬN}

Nghiên cứu cho thấy giá trị qHBsAg giảm có ý nghĩa tại thời điểm 24 tuần trong quá trình điều trị TDF, tuy nhiên giá trị qHBsAg giảm không có ý nghĩa trong quá trình điều trị TAF thời gian ngắn. Trong tương lai cần có nhiều nghiên cứu với cõ̃ mẫu lớn hơn, đa trung tâm và thời gian theo dõi dài hơn đến đánh giá vai trò của qHBsAg trong quá trình điều trị.

\section{TÀI LIÊU THAM KHẢO}

1. World Health Organization. Guidelines for the Prevention, Care and Treatment of Persons with Chronic Hepatitis B Infection. 2015. https://apps. whoint/iris.

2. Hipgrave D B, Nguyen $T$ V, Vu M H, Hoang $T$ $\mathbf{L}$, et al. Hepatitis $B$ infection in rural Vietnam and the implications for a national program of infant immunization. American Journal of Tropical Medicine and Hygiene. 2003; 69(3): 288-294.

3. Gao $Y$, Li $Y$, Meng $Q$, Zhang $Z$, et al. Serum Hepatitis B Virus DNA, RNA, and HBsAg: Which Correlated Better with Intrahepatic Covalently
Closed Circular DNA before and after Nucleos(t)ide Analogue Treatment?. Journal of Clinical Microbiology. 2017; 55(10): 2972-2982.

4. Yang J, Chen J, Ye $P$, Jin $L$, et al. HBsAg as an important predictor of $\mathrm{HBeAg}$ seroconversion following antiviral treatment for $\mathrm{HBeAg}$-positive chronic hepatitis B patients. Journal of Translational Medicine. 2014; 12: 183.

5. Boglione L, D'Avolio A, Cariti G, Gregori G, et al. Kinetics and prediction of HBsAg loss during therapy with analogues in patients affected by chronic hepatitis $\mathrm{B}$ HBeAg negative and genotype D. Liver International. 2013; 33(4): 580-585.

6. Yang N, Feng J, Zhou T, Li Z, et al. Relationship between serum quantitative HBsAg and HBV DNA levels in chronic hepatitis B patients. Journal of Medical Virology. 2018; 90(7): 1240-1245.

7. Lee J H, Kím S J, Ahn S $H$, Lee J, et al. Correlation between quantitative serum HBsAg and HBV DNA test in Korean patients who showed high level of HbsAg. Journal of Clinical Pathology. 2010; 63 (11): 1027-1031

8. Liu $X$, Chen J M, Lou J L, Huang $Y X_{\text {, et al. }}$ Correlation between hepatitis B virus DNA levels and diagnostic tests for HBsAg, HBeAg, and PreS1$\mathrm{Ag}$ in chronic hepatitis B. Genetics and Molecular Research. 2016; 15(2): 1-9.

\title{
KHẢO SÁT ĐĂC ĐIỂM THIẾU MÁU Ở BỆNH NHÂN BỆNH THẬN MẬN GIAI ĐOẠN CUỐI LỌC MÁU CHU KỲ
}

\section{TÓM TẮT}

Mục tiêu nghiên cứu: Khảo sát đặc điểm thiếu máu và một số yếu tố liên quan đến thiếu máu ở bệnh nhân bệnh thận mạn giai đoạn cuối lọc máu chu kỳ. Phương pháp nghiên cứu: Nghiên cứu mô tả cằt ngang được thực hiên để khảo sát đặc điểm thiếu máu và các yếu tố liền quan ở 130 bệnh nhân bệnh thân mạn giai đoạn cuối lọc máu chu kỳ tai khoa Nội thẩn - thận nhân tạo Bệnh viện hữu ngḥi đa khoa Nghệ An. Kết quả: Tỷ lệ bệnh nhân bệnh thận mạn giai đoạn cuối lọc máu chu kỳ có thiếu máu là $92,3 \%$. Thiếu máu nhẹ chiếm tỷ lệ cao nhất $(48,5 \%)$, thiếu máu vứa chiếm tỷ lệ $37,7 \%$ và thiếu máu mức độ nặng chiếm tỷ lệ $6,2 \%$. Thiếu máu đẳng sắc là loại thiếu máu thường gặp nhất ở bệnh nhân bệnh thận mạn giai đoạn cuối lọc máu chu kỳ $(83,3 \%)$. Có mối liên quan giứa mức độ thiếu máu với tình trạng dinh dưỡng của bệnh nhân. Kết luận: Thiếu máu còn chiếm tỷ lệ cao ở bệnh nhân bệnh thận mạn giai

\section{*Đai hoc Y khoa Vinh}

Chịu trách nhiệm chính: Nguyễn Văn Tuấn

Email: tuanminh1975@gmail.com

Ngày nhận bài: 13.4.2021

Ngày phản biện khoa học: 26.5.2021

Ngày duyệt bài: 10.6.2021

\section{Nguyễn Văn Tuấn*, Trần Thị Anh Tho*}

đoạn cuối lọc máu chu kỳ. Có mối liên quan giữa mức độ thiếu máu với tình trạng dinh dưỡng của bệnh nhân.

Tứ khóa: thiếu máu, bệnh thận mạn giai đoạn cuối

\section{SUMMARY \\ SURVEYING ANEMIA'S CHARACTERISTICS OF PATIENTS WITH END STAGE RENAL DISEASE ON DIALYSIS}

Objective: To investigate the characteristics of anemia and some factors related to anemia in patients with end-stage renal disease (ESRD) on dialysis. Method: A cross-sectional descriptive study was conducted to investigate the characteristics of anemia and factors related to anemia in 130 patients with ESRD on dialysis at the Department of Internal Medicine - Hemodialysis at the Nghe An Friendship General Hospital. Results: Prevalence of patients with ESRD on dialysis that had anemia is $92,3 \%$. Propotion of patients with mild anemia was highest $(48,5 \%)$, propotion of patients with moderate anemia was $37,7 \%$ and proportion of patients with severity anemia was $6,2 \%$. Ormochromic anemia was the most common type of anemia in patients with ESRD on dialysis $(83,3 \%)$. There was a relationship between the degree of anemia and the nutritional status of the patient. Conclusions: The proportion of anemia was high in patients with ESRD on dialysis. There was a 
relationship between the degree of anemia and the nutritional status of the patient.

Keywords: Anemia, ESRD

\section{I. ĐĂT VẤN ĐỀ}

Thiếu máu là môt vấn đề thường gặp ở bênh nhân bệnh thận mạn. Điều hòa sản xuất hồng câu là một trong những chức năng nội tiết chính của thận, vì vậy dù nguyên nhân khởi bệnh là ở câu thận, hay ống kẽ thận... thì khi thận suy đều gây triệu chứng thiếu máu. Thận càng suy thì mức độ thiếu máu càng nặng. Thiếu máu, ngay từ giai đoạn đâuu của bệnh thận mạn có thể làm bệnh nhân mệt mỏi, suy giảm khả năng tập trung, suy giảm trí nhớ, làm ảnh hưởng đến hiệu quả công việc và cuộc sống hàng ngày của bệnh nhân. Ngoài ra, thiếu máu có thể dẫn tới suy tim, làm thúc đầy sớm hơn tiến triển của bệnh thận mạn và gây ra hàng loạt những biến chứng về tim mạch, thân kinh, ... làm tăng nguy cơ tử vong cho bệnh nhân. Mức độ thiếu máu ở bệnh nhân bệnh thận mạn còn phụ thuộc vào một số yếu tố khác như dinh dưỡng, mức độ tuân thủ điêu trị... Chúng tôi tiến hành nghiên cứu đề tài này nhằm mục tiêu: Khảo sát đặc điểm thiếu máu và một số yếu tố liên quan đến thiếu máu ở bệnh nhân bệnh thận mạn giai đoạn cuối lọc máu chu kỳ.

\section{II. ĐỐI TƯợNG VÀ PHƯƠNG PHÁP NGHIÊN CỨU}

\section{1. Đối tượng nghiên cứu}

- Tiêu chuẩn lưa chơn: Bệnh nhân được chẩn đoán bệnh thận mạn giai đoạn cuối lọc máu chu kỳ và đồng ý tham gia nghiên cứu.

- Tiêu chuấn loại trư:

+ Bệnh nhân có dấu hiệu mất máu: chấn thương, xuất huyết tiêu hóa...

+ Bệnh nhân đang trong tình trạng nhiễm trùng cấp tính.

2.2. Địa điểm nghiên cứu: Khoa Nội thận Thận nhân tạo, Bệnh viện Hữu nghị đa khoa Nghệ An.

\subsection{Phương pháp nghiên cứu}

2.3.1. Thiết kế nghiên cứu: Nghiên cứu mô tả cắt ngang

2.3.2. Cõ mẫu: 130 bệnh nhân bệnh thận mạn giai đoạn cuối lọc máu chu kỳ thõa mã்n tiêu chuẩn lựa chọn đối tượng nghiên cứu.

\subsubsection{Các tiêu chuẩn áp dụng trong} nghiên cứu

- Chẩn đoán thiếu máu theo tiêu chuẩn của Hội Tiết niệu - Thận học Việt Nam - 2013: Ở người trên 15 tuổi mắc bệnh thận mạn được chẩn đoán thiếu máu khi: nồng độ hemoglobin thấp hơn $130 \mathrm{~g} / \mathrm{l}$ ở nam và $120 \mathrm{~g} / \mathrm{l}$ ở nữ [1].
- Phân loại thiếu máu theo đặc điểm huyết học [3]

\begin{tabular}{|c|c|c|c|}
\hline \multicolumn{2}{|c|}{ Phân loại thiếu máu } & \multicolumn{2}{|c|}{$\begin{array}{c}\text { Các chỉ số MCV, } \\
\text { MCHC }\end{array}$} \\
\hline \multicolumn{2}{|c|}{$\begin{array}{l}\text { Thiếu máu nhược sắc, } \\
\text { hồng cầu nhỏ }\end{array}$} & \multicolumn{2}{|c|}{$\begin{aligned} \mathrm{MCHC} & <300(\mathrm{~g} / \mathrm{l}) \\
\mathrm{MCV} & <80(\mathrm{fL})\end{aligned}$} \\
\hline \multicolumn{2}{|c|}{$\begin{array}{l}\text { Thiếu máu đằng sắc, } \\
\text { hồng câuu bình thường }\end{array}$} & \multicolumn{2}{|c|}{$\begin{array}{l}\text { MCHC: } 320-360(\mathrm{~g} / \mathrm{l}) \\
\text { MCV: } 85-95(\mathrm{fL})\end{array}$} \\
\hline \multicolumn{2}{|c|}{ Thiếu máu hông câu to } & \multicolumn{2}{|c|}{$\mathrm{MCV}>100(\mathrm{fL})$} \\
\hline \multicolumn{4}{|c|}{$\begin{array}{l}\text { - Phân loại mức độ thiếu máu theo Bạch } \\
\text { Quốc Tuyên-1984 [2] }\end{array}$} \\
\hline $\begin{array}{c}\text { Mức độ } \\
\text { thiêu } \\
\text { máu }\end{array}$ & $\begin{array}{l}\text { hemoglobin } \\
(\mathrm{g} / \mathrm{I})\end{array}$ & Hông câu & \\
\hline Nhẹ & 0 & $3,1-3,69$ & $0,31-0,369$ \\
\hline Vừa & & $2,0-3,0$ & $0,2-0,3$ \\
\hline Nặng & $<60$ & $<2,0$ & \\
\hline
\end{tabular}

2.4. Xử lý số liệu: - Số liệu được xử lý bằng phần mềm SPSS 20.0.

- Sử dụng ANOVA test để so sánh trung bình các quan sát nếu biến có phân bố chuẩn.

- Sử dụng test X2 để so sánh sự khác biệt về tỷ lệ phân trăm.

\section{KẾT QUẢ NGHIÊN CỨU}

\section{1. Đặc điểm chung của đối tượng} nghiên cứu

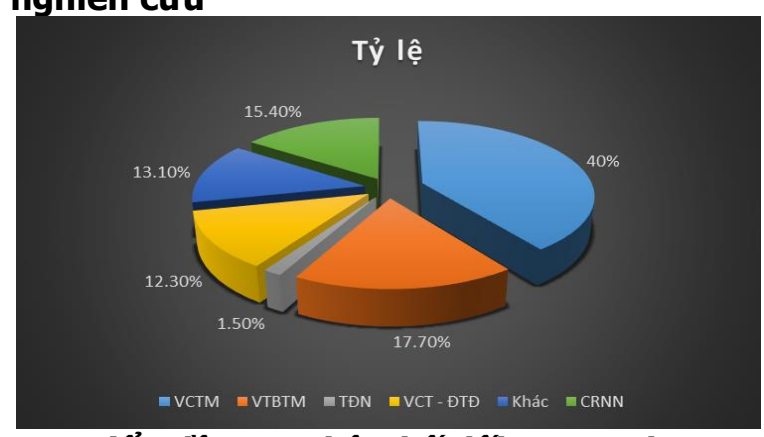

Biểu đồ 3.1. Phân bố đôi tượng theo nguyên nhân bệnh thận mạn

Nhân xét: Viêm câu thận mạn là nguyên nhân hàng đâu gây ESRD (40\%), tiếp theo đó là viêm thận bể thận mạn $(17,7 \%)(p<0,05)$.

Bảng 3.1. Phân bố đối tượng nghiên cứu theo vưng sinh sống

\begin{tabular}{|c|c|c|c|c|c|}
\hline \multirow{2}{*}{\multicolumn{2}{|c|}{}} & \multicolumn{4}{c|}{ Phân bố } \\
\cline { 3 - 6 } \multicolumn{2}{|c|}{} & \multicolumn{2}{|c|}{ Thành thị } & \multicolumn{2}{c|}{ Nông thôn } \\
\cline { 3 - 6 } & $\mathbf{n}$ & $\mathbf{\%}$ & $\mathbf{n}$ & $\mathbf{\%}$ \\
\hline \multirow{2}{*}{$\begin{array}{c}\text { Giới } \\
\text { tính }\end{array}$} & Nữ & 11 & 8,5 & 43 & 33,1 \\
\cline { 2 - 6 } & Nam & 13 & 10,0 & 63 & 48,5 \\
\hline \multicolumn{2}{|c|}{ Tổng } & $\mathbf{2 4}$ & $\mathbf{1 8 , 5}$ & $\mathbf{1 0 6}$ & $\mathbf{8 1 , 5}$ \\
\hline
\end{tabular}

Nhân xét: Phần đông bệnh nhân ở nông thôn. Không có sự khác biệt về tỷ lệ nam và nữ ở cả vùng nông thôn và vưng thành thị $(p>0,05)$. 
Bảng 3.2. Các triệu chứng lâm sàng của đôi tượng nghiên cứu ở thời điểm vào viện

\begin{tabular}{|c|c|c|c|c|c|}
\hline Triệu chứng cơ năng & $\mathbf{n}$ & $\mathbf{\%}$ & Triệu chứng thực thế & $\mathbf{n}$ & $\mathbf{\%}$ \\
\hline Mệt mói & 109 & 83,8 & Da xanh-NM nhợt & 105 & 80,8 \\
\hline Buồn nôn-nôn & 41 & 31,5 & Phù & 120 & 92,3 \\
\hline Chán ăn & 69 & 53,1 & THA & 92 & 70,8 \\
\hline Khó thở & 20 & 15,4 & Xuất huyết & 26 & 20,0 \\
\hline Dau đâu & 43 & 33,1 & Suy tim & 14 & 10,8 \\
\hline Đau ngực & 15 & 11,5 & VDTKNV & 4 & 3,1 \\
\hline Đau thắt lưng & 43 & 33,1 & Hôn mê & 0 & 0,0 \\
\hline Ngứa & 26 & 20,0 & & & \\
\hline Chuôot rút & $\mathbf{3 2}$ & $\mathbf{2 4 , 6}$ & & & \\
\hline
\end{tabular}

Nhân xét: Phù là triêu chứng hay gặp nhất ở bênh nhân ESRD lọc máu chu kỳ (chiếm 92,3\%). Các triệu chứng khác như da xanh, niêm mạc nhợt, mệt mỏi, chán ăn, tăng huyết áp cũng chiếm tỷ lệ cao.

Bảng 3.3. Xét nghiệm sinh hóa máu của đôi tượng nghiên cứu

\begin{tabular}{|c|c|c|}
\hline \multicolumn{2}{|c|}{ Xét nghiệm } & Trung bình \pm SD \\
\hline & & $28,54 \pm 6,80$ \\
\hline \multicolumn{2}{|c|}{ Creatinin } & $767,39 \pm 229,99$ \\
\hline \multirow{2}{*}{ Acid uric } & Nam & $505,54 \pm 116,19$ \\
\hline & Nữ & $496,82 \pm 128,70$ \\
\hline \multirow{2}{*}{$\begin{array}{c}\text { Sắt huyết } \\
\text { thanh }\end{array}$} & Nam & $14,08 \pm 2,90$ \\
\hline & Nữ & $12,12 \pm 4,14$ \\
\hline \multicolumn{2}{|c|}{ Protid } & $69,8 \pm 8,2$ \\
\hline \multicolumn{2}{|c|}{ Albumin } & $38,29 \pm 4,84$ \\
\hline \multicolumn{2}{|c|}{ Ferritin } & $401,62 \pm 343,48$ \\
\hline \multicolumn{2}{|c|}{$\mathrm{Na}^{+}$} & $4,69 \pm 0,78$ \\
\hline \multicolumn{2}{|c|}{$\mathrm{K}^{+}$} & $139,35 \pm 3,53$ \\
\hline \multicolumn{2}{|c|}{$\mathrm{Ca}^{2+}$} & $2,14 \pm 0,24$ \\
\hline
\end{tabular}

3.2. Đăc điểm thiếu máu của đôi tượng nghiên cứu

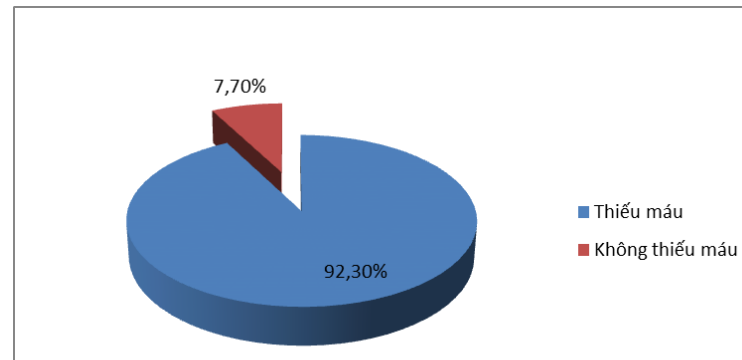

Biểu đồ 3.2. Tỷ lệ thiếu máu của đối tượng nghiên cứu

Nhận xét: Hầu hết bệnh nhân ESRD lọc máu chu kỳ đều có tình trạng thiếu máu (chiếm $92,3 \%)$.

Bảng 3.4. Mức độ thiếu máu của đôî tượng nghiên cứu

\begin{tabular}{|c|c|c|c|c|c|c|c|}
\hline \multicolumn{7}{|c|}{ Mức độ thiếu máu } \\
\hline \multicolumn{2}{|c|}{ Không thiếu máu } & \multicolumn{2}{c|}{ Thiếu máu nhẹ } & \multicolumn{2}{c|}{ Thiếu máu vừa } & \multicolumn{2}{c|}{ Thiếu máu nặng } \\
\hline $\mathrm{n}$ & $\%$ & $\mathrm{n}$ & $\%$ & $\mathrm{n}$ & $\%$ & $\mathrm{n}$ & $\%$ \\
\hline 10 & 7,7 & 63 & 48,5 & 49 & 37,7 & 8 & 6,2 \\
\hline
\end{tabular}

Nhân xét: Thiếu máu nhẹ chiếm tỷ lệ cao nhất $(48,5 \%)$, thiếu máu vừa chiếm tỷ lệ $37,7 \%$. Trong tổng số 130 bệnh nhân, có 8 bệnh nhân thiếu máu nặng (6,2\%).

Bảng 3.5. Đặc điểm thiếu máu cảu đối tượng nghiên cứu dựa vào xét nghiệm huyêt học

\begin{tabular}{|c|c|c|}
\hline Đặc điếm huyết họcc & $\mathbf{n}$ & $\mathbf{\%}$ \\
\hline Thiếu máu đắng sắc & 100 & 83,3 \\
\hline Thiếu máu nhược sắc & 15 & 12,5 \\
\hline Thiếu máu hồng câuu to & 5 & 4,2 \\
\hline
\end{tabular}

Nhận xét: Thiếu máu đẳng sắc là loại thiếu máu thường gặp nhất ở bệnh nhân ESRD lọc máu chu kỳ.

Bảng 3.6. Liên quan giữa thiếu máu với các yêu tố lâm sàng của đôii tượng nghiên cứu

\begin{tabular}{|c|c|c|c|c|c|c|c|c|}
\hline \multirow{3}{*}{\multicolumn{2}{|c|}{ Yếu tố }} & \multicolumn{6}{|c|}{ Mức độ thiếu máu } & \multirow{3}{*}{$\mathbf{p}$} \\
\hline & & \multicolumn{2}{|c|}{ Nhẹ } & \multicolumn{2}{|c|}{ Vừa } & \multicolumn{2}{|c|}{ Nặng } & \\
\hline & & $\mathbf{n}$ & $\%$ & $\mathbf{n}$ & $\%$ & $\mathbf{n}$ & $\%$ & \\
\hline \multirow{2}{*}{ Nơi sinh sống } & Thành thị & 8 & 6,2 & 11 & 8,5 & 0 & 0 & \multirow{2}{*}{$p>0,05$} \\
\hline & Nông thôn & 55 & 42,3 & 38 & 29,2 & 8 & 6,2 & \\
\hline \multirow{2}{*}{$\begin{array}{l}\text { Trình độ } \\
\text { học vấn }\end{array}$} & Cấp 1 & 5 & 4,2 & 4 & 3,3 & 0 & 0 & \multirow{2}{*}{$p>0,05$} \\
\hline & Cấp 2 & 24 & 20 & 9 & 7,5 & 2 & 1,7 & \\
\hline
\end{tabular}


VIETNAM MEDICAL JOURNAL N²2 - JUNE - 2021

\begin{tabular}{|c|c|c|c|c|c|c|c|c|}
\hline & Từ cấp 3 trở lên & 34 & 28,3 & 37 & 30,8 & 5 & 4,2 & \multirow{3}{*}{$p>0,05$} \\
\hline \multirow{2}{*}{ Giới tính } & Nam & 38 & 29,2 & 28 & 21,5 & 4 & 3,1 & \\
\hline & Nữ & 25 & 19,2 & 21 & 16,2 & 4 & 3,1 & \\
\hline \multirow{3}{*}{ Nhóm tuổi } & $<40$ & 21 & 16,2 & 20 & 15,4 & 4 & 3,1 & \multirow{3}{*}{$p>0,05$} \\
\hline & $40-59$ & 26 & 20,0 & 23 & 17,7 & 1 & 0,8 & \\
\hline & $\geq 60$ & 16 & 12,3 & 6 & 4,6 & 3 & 2,3 & \\
\hline \multirow{3}{*}{$\begin{array}{l}\text { Thời gian } \\
\text { lọc máu }\end{array}$} & 1 năm & 25 & 20,8 & 21 & 17,5 & 4 & 3,1 & \multirow{3}{*}{$p>0,05$} \\
\hline & 1 năm & 30 & 25 & 23 & 19,2 & 3 & 2,3 & \\
\hline & 5 năm & 8 & 6,7 & 6 & 5 & 0 & 0 & \\
\hline \multirow{3}{*}{$\begin{array}{l}\text { Tình traang } \\
\text { dinh dưỡng } \\
\text { (BMI) }\end{array}$} & Gầy & 7 & 5,4 & 14 & 10,8 & 3 & 2,3 & \multirow{3}{*}{$p<0,05$} \\
\hline & Bình thường & 51 & 39,2 & 35 & 26,9 & 4 & 3,3 & \\
\hline & Thừa cân & 5 & 3,8 & 1 & 0,8 & 0 & 0 & \\
\hline
\end{tabular}

Nhận xét: Có mối liên quan giữa mức độ thiếu máu với tình trạng dinh dưỡng của đối tượng nghiên cứu $(p<0,05)$.

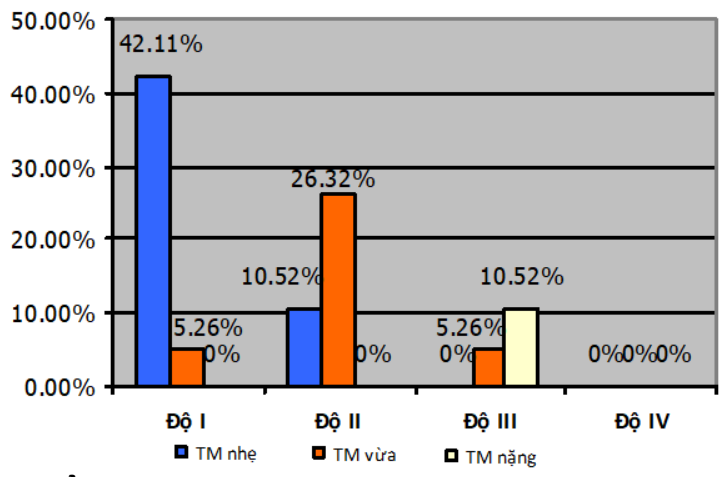

Biểu đồ 3.3. Mức độ thiếu máu theo mức độ suy tim của đôi tượng nghiên cứu

Nhận xét: Thiếu máu nhe thường gặp ở những bệnh nhân suy tim độ I. Thiếu máu nặng gặp ở bệnh nhân suy tim độ III (chiếm 10,52\%). Không có bệnh nhân nào suy tim độ IV. Mối liên quan giữa mức độ suy tim và mức độ thiếu máu có ý nghĩa thống kê $(p<0,05)$.

\section{BÀN LUÂN}

4.1. Đặc điểm chung của đối tượng nghiên cứu. Trong nghiên cứu của chúng tôi, đa số bệnh nhân ở nông thôn chiếm $81,5 \%$ và bệnh nhân ở thành thị chiếm chỉ chiếm 18,5\%. Trong số 130 bệnh nhân nghiên cứu có 75 bệnh nhân nam chiếm $57,7 \%$ và 55 bênh nhân nữ chiếm $42,3 \%$. Trong môt báo cáo của Lynsey Webb và cộng sự (2009) tại Mỹ cho thấy tỷ lệ mắc bệnh thận mạn của nam so với nữa là $1,5 / 1$ [8]

Tỷ lệ mắc bệnh bệnh thận mạn giữa hai giới khác nhau có thể liên quan đến nguyên nhân dẫn đến bệnh thận mạn. Theo nghiên cứu của Hoa Kỳ năm 1997, trong bệnh viêm cầu thận, nam chiếm $70,7 \%$, nữ chiếm 29,3\%; trong bệnh viêm bể thận, nam chiếm $64,3 \%$, nữ chiếm $35,7 \%$. Trong một nghiên cứu của Kammerer J và cộng sự cho thấy tỷ lệ bệnh nhân nam chiếm $52,8 \%$ và bệnh nhân nữ chiếm 47,2\% [7].
Trong nghiên cứu này, độ tuổi của bệnh nhân chủ yếu là 20 - 59 chiếm tỷ lệ 78,5\%; nhóm đối tượng từ 60 tuổi trở lên chiếm 21,5\%. Tuổi trung bình của nhóm nghiên cứu là 47 tuổi, thấp hơn so với nghiên cứu của Hoa Kỳ năm 1997 là 61 tuổi. Như vậy bệnh nhân trong nghiên cứu của chúng tôi chủ yểu ở độ tuổi 20 - 59. Đây là độ tuổi lao động vì vậy ảnh hưởng của bệnh đến cuộc sống và công việc của họ là không nhỏ, từ đó trực tiếp ảnh hưởng đến nền kinh tế xã hội và chi phí chăm sóc y tế. Báo cáo của Saydah S. và cộng sự ở Hoa Kỳ cho thấy phân bố theo độ tuổi của bệnh nhân bệnh thận mạn giai đoạn 1994 - 2004: nhóm từ 20-39 tuổi chiếm 35.7\%; nhóm từ 40-59 tuổi chiếm 30,1\%, nhóm từ 60 tuổi trở lên chiếm 34,2\% [10].

Trong nghiên cứu này, số bệnh nhân có triệu chứng phù chiếm tỷ lệ cao (92,3\%), tiếp theo đó là mệt mỏi $(83,8 \%)$, tăng huyết áp $(70,8 \%)$, chán ăn $(53,1 \%)$, buồn nôn - nôn $(31,5 \%)$. Tuy nhiên mệt mỏi hay chán ăn là một triệu chứng cơ năng mang tính chủ quan. Do đó, bệnh nhân bệnh thận mạn có thể bị suy dinh dưỡng nếu kèm theo chế độ ăn kiêng đạm. Triệu chứng đau đầu cũng chiếm tỷ lệ cao (33,1\%). Nghiên cứu của Fliss E. M. Murtagh và cộng sự (2007) tại Anh cho thây tỷ lệ gặp các triệu chứng ở bệnh nhân bệnh thận mạn lọc máu chu kỳ: mệt mỏi $(71 \%)$, chán ăn $(49 \%)$, khó thở $(35 \%)$, buồn nôn - nôn (33\%), ngứa (55\%) [6].

4.2. Đặc điểm thiếu máu của đối tượng nghiên cứu. Thiếu máu là một triệu chứng hẳng định ở bệnh nhân bị bệnh thận mạn [9]. Trong nghiên cứu của chúng tôi nồng độ huyết sắc tố trung bình của đối tượng nghiên cứu là $94,34 \pm 19,91 \mathrm{~g} / \mathrm{l}$. Kết quả này của chúng tôi thấp hơn so với kết quả một nghiên cứu ở Hoa Kỳ năm 2004 với nồng độ huyết sắc tố trung bình là $122 \pm 16 \mathrm{~g} / \mathrm{l}$. Điều này chứng tỏ tình trang thiếu máu ở bệnh nhân bệnh thận mạn ở nước 
ta vẫn là môt vấn đề cần phải quan tâm mă̆c dù việc điều trị thiếu máu cho bệnh nhân bệnh thận mạn đã được cải thiện đáng kể trong những năm gần đây nhờ sử dụng rHu - EPO. Biểu đồ 3.2 cho thấy thiếu máu là biểu hiện hay gặp ở bệnh nhân bệnh thận mạn lọc máu chu kỳ, chiếm 92,3\%. Trong đó, thiếu máu nhe chiếm tỳ lệ cao nhất là $48,5 \%$, thiếu máu vừa (hay thiếu máu trung bình) chiếm $37,7 \%$, có 8 bệnh nhân bị thiếu máu nặng chiếm 6,2\% (bảng 3.4). Báo cáo của Kammerer J và cộng sự ở Hoa Kỳ về tình trạng thiếu máu ở bệnh nhân bệnh thận mạn từ năm 1999 - 2000 cho thấy: tỷ lệ thiếu máu chiếm $78 \%$, trong đó có $51,7 \%$ thiếu máu nhẹ, 26,3\% thiếu máu trung bình, không có bệnh nhân nào có thiếu máu nặng. Trong một nghiên cứu của Birhie Alemu và cộng sự ở Ethiopia năm 2020 ở bệnh nhân bệnh thận mạn cho thây tỷ lệ thiếu máu chung là $53,3 \%$ và mức độ thiếu máu liên quan với giai đoạn bệnh thận mạn [4].

Một nghiên cứu về tình trạng thiếu máu trên bệnh nhân bệnh thận mạn giai đoạn cuối lọc máu chu kỳ ở Nigieria cho thấy: thiếu máu chiếm $87 \%$, trong đó thiếu máu mức độ nhe đến trung bình chiếm $69 \%$, thiếu máu nặng chiếm $18 \%$.

Giá trị MCV trung bình của đối tượng nghiên cứu là $88,16 \pm 7,71 \mathrm{fL}$, giá trị $\mathrm{MCH}$ trung bình là $28,65 \pm 2,88 \mathrm{pg}$, giá trị MVHC trung bình là $317,30 \pm 29,78 \mathrm{~g} / \mathrm{l}$. Kết quả ở bảng 3.4 cho thấy thiếu máu ở bệnh nhân bệnh thận mạn chủ yếu là thiếu máu đẳng sắc hồng cầu bình thường chiếm $83,3 \%$, thiếu máu nhược sắc hồng cầu nhỏ chiếm $12,5 \%$, thiếu máu hồng cầu to chiếm $4,2 \%$. Kết quả nghiên cứu của chúng tôi tương tự so với một nghiên cứu khác ở Iran (2010): thiếu máu đẳng sắc, hồng cầu bình thường chiếm $80 \%$; thiếu máu nhược sắc, hồng cầu nhỏ chiếm $15 \%$ và thiếu máu hồng cầu to chiếm $5 \%$.

Thiếu máu nhược sắc, kích thước hồng cầu nhỏ và thiếu máu hồng cầu to có thể liên quan đến vấn đề thiếu chất dinh dưỡng như sắt, vitamin B12, acid folic... đối với bệnh nhân bệnh thận mạn, đặc biệt là bệnh nhân có thu nhập thấp, không đủ điểu kiện để cải thiện tình trạng dinh dưỡng. Một yếu tố quan trọng khác là do bệnh nhân có chế độ ăn kiêng đạm chặt chẽ, cùng với tình trạng chán ăn, ăn khồng ngon, rối loạn tiêu hóa... vì vậy dễ dẫn đến tình trạng suy dinh dưỡng.

Bảng 3.3 cho thãy nồng độ sắt huyết thanh trung bình ở nhóm đối tượng nghiên cứu của chúng tôi là $14,08 \pm 2,90 \mu \mathrm{mol} / /$ đối với nam và $12,12 \pm 4,14 \mu \mathrm{mol} / \mathrm{l}$ đối với nữ. Nồng độ ferritin huyết thanh trung bình ở nhóm đối tượng nghiên cứu là $401,62 \pm 343,48 \mathrm{ng} / \mathrm{ml}$. Trong đó, có 10 bệnh nhân có ferritin trên $1000 \mathrm{ng} / \mathrm{ml}$, chiếm $7,7 \%$.

ở bệnh nhân bệnh thận mạn, thiếu sắt góp phần gẩy thiếu máu. Thiếu sắt do nhiều nguyên nhân như chế độ ăn thiếu sắt, chảy máu kinh niên, kém hấp thu... Vì vậy, trước khi điều trị thiếu máu bằng rHu-EPO cần phải điều chỉnh lượng sắt trong cơ thể một cách thích hợp nhất để đat hiêu quả điêu trị cao nhất với rHu-EPO. Nhưng vấn đề ứ sắt (hay quá tải sắt) cũng đóng vai trò quan trọng ảnh hưởng đến tình trạng thiếu máu ở bềnh nhân bênh thân mạn. Điều này có thể giải thích bởi khi sắt dư thừa dẫn đến việc ức chế quá trình sinh máu ở tủy xương, tích tụ ở các cơ quan sinh các gốc tứ do, gây tăng nguy cơ xơ vữa đônng mach, nhiếm trùng và có thể dẫn đễn tử vong đổi với bệnh nhân bệnh thận mạn giai đoạn cuối. Theo nghiên cứu của các tác giả tại Ba Lan năm 1996, nhóm bệnh nhân không điều trị rHu-EPO có nồng độ EPO máu và dư trữ sắt thấp hơn so với nhóm bệnh nhân được điều trị rHu-EPO. Qua nghiên cứu cả hai nhóm, thấy có mối tương quan nghịch giữa nồng độ EPO và dự trữ sắt. Như vậy, trước khi và song song điều trị thiếu máu bằng rHu-EPO, cần phải theo dõi dự trữ sắt ở bệnh nhân bệnh thận mạn để đạt được hiệu quả điều trị cao nhất.

Trong nghiên cứu của chúng tôi cho thấy có mối liên quan giữa tình trạng thiếu máu với tình trạng dinh dưỡng của bệnh nhân, ở nhóm bệnh nhân có thể trạng gầy thì tỷ lệ thiếu máu cao hơn có ý nghĩa thống kê so với nhóm bệnh nhân có thể trạng bình thường với $p<0,05$. Nghiên cứu của Bárány $P$. và cộng sự cũng cho thấy có mối liên quan giữa tình trạng dinh dưỡng với thiếu máu ở bệnh nhân bệnh thận mạn giai đoạn cuối lọc máu chu kỳ đã điêu trị bằng erythropoietin [5]. Trong nghiên cứu của chúng tôi cũng nhận thây có mối liên quan giữa mức độ suy tim và mức độ thiếu máu, thiếu máu nặng gặp nhiều hơn ở những bệnh nhân có mức độ suy tim nặng hơn. Nghiên cứu của Chu Thị Giang cũng cho thấy, nhóm bệnh nhân suy tim có thiếu máu có nguy cơ bị suy tim nặng hơn nhóm bệnh nhân không có thiếu máu gấp 2,23 lần.

\section{KẾT LUẬN}

- Tỷ lệ bệnh nhân ESRD lọc máu chu kỳ có thiếu máu là 92,3\%.

- Thiếu máu nhẹ chiếm tỷ lệ cao nhất $(48,5 \%)$, thiếu máu vừa chiếm tỷ lệ $37,7 \%$ và thiếu máu mức độ nặng chiếm tỷ lệ 6, $2 \%$.

- Thiếu máu đẳng sắc là loại thiếu máu thường gặp nhất ở bệnh nhân ESRD lọc máu chu 
kỳ $(83,3 \%)$.

- Có mối liên quan giữa mức độ thiếu máu với tình trạng dinh dưỡng của bệnh nhân.

\section{TÀI LIÊU THAM KHẢO}

1. Hội Tiết niệu Thận học Việt Nam (2013), Chẩn đoán và đánh giá thiếu máu trong bệnh thân mạn, Hướng dẫn điêu trị thiếu máu trong bệnh thần man. tr. 10-11.

2. Bạch Quốc Tuyên (2002), Đại cương về thiếu máu, Bách khoa thư bệnh học. Tập 1, Nhà xuất bản Y học.

3. Hà Thi Thanh (2009), Chương huyết học cở sở. Huyết học - truyên máu. Nhà xuất bản $Y$ học.

4. Alemu B, et al (2021), Prevalence of Anemia and Its Associated Factors Among Chronic Kidney Disease Patients Attending Selected Public Hospitals of Addis Ababa, Ethiopia: InstitutionalBased Cross-Sectional Study. Original Research. 14-2021: p. 67-75.
5. Bárány $\mathbf{P}$, et al (1991), Nutritional assessment in anemic hemodialysis patients treated with recombinant human erythropoietin. Clin Nephrol. 35(6): p. 370-379.

6. Fliss E. M. Murtagh, J.A.H., Irene J.Higginson (2007), The prevalence of symptoms in ERSD: a systematic review. Advances in CKD-the journal of the national kidney foundation. 14(1): p. 82-99.

7. Kammerer J, et al (2002), Anemia in CKD: prevalence, diagnosis and treatment. Case study of the anemic patient. Nephrol nursing journal. 29(4): p. 371-374.

8. Lynsey Webb, et al (2009), Demographic and biochemistry profile of kidney transphant rcipients in the $\mathrm{U} \mathrm{K}$ in 2008: national and centre-specific analyses, The 12th Annual report from the UK renal registry. p. 69-102.

9. Maria Amélia Aguiar Hazin (2020), Anemia in chronic kidney disease. Revista da Associação Médica Brasileira. 66.

\section{SẢN XUẤT THUỐC BẰNG CÔNG NGHÊ IN 3D FDM PHẦN 1: NGUYÊN LÝ VÀ QUY TRÌNH HOẠT ĐộNG}

\section{TÓM TẮT}

In 3D là công nghệ tạo vật thể 3 chiều có nhiều triển vọng trong việc bào chế thuốc cá nhân hóa đáp ứng nhu câu điều trị riêng biệt cùng từng người bệnh. Công ghệ này đồng thời cho phép bào chế các dạng thuốc với liêu lượng chính xác, có cấu trúc phức tạp kiểm soát giải phóng chỉ bằng một vài cái nhấp chuột máy tính. Bài tổng quan này trình bày một cách có hệ thống nguyên lý cấu tạo, cơ chế hoạt động của máy in 3D ứng dụng phổ biến trong nghành Dược. Bên cạnh đó, bài viết mô tả chi tiết quy trình từng bước tạo ra một vật thể bằng kỹ thuật in $3 \mathrm{D}$ dựa trên nguyền lý FDM (fused deposition modeling).

Tứ khóa: Công nghệ in 3D, thuốc in 3D, cá nhân hóa điều trị.

\section{SUMMARY}

\section{APPLICATION OF 3D FDM IN \\ PHARMACEUTICAL FORMULATION DESIGN: OPERATION FUNDAMETAL AND TECHNICAL CHALLENGES}

3 dimension (3D) printing was utilized, for the first time, as a manufacturing platform for fabrication of pharmaceutical dosage forms in 2000 [1]. However, not until the first approval of Spritam by US. FDA in 2015, application of 3D printing in pharmaceutical

*Trường đại hoc Dước Hà Nôi

Chịu trách nhiệm chính: Võ Quốc Ánh

Email: anhvq@hup.edu.vn

Ngày nhận bài: 13.4.2021

Ngày phản biên khoa học: 27.5.2021

Ngày duyệt bài: 11.6.2021
Lê Thị Thu Trang*, Trần Thị Hải Yến*, Nguyễn Thị Thanh Duyên*, Võ Quốc Ánh*

sciences gained its growing interest. The technology is involving in the layer-by-layer deposition of materials to fabricate 3 dimension objects according to a digital model. The American Society for Testing and Materials (ASTM) classified 3D printing technology into 7 categories, namely material extrusion, material jetting, powder bed fusion, binder jetting, vat photopolymerisation, sheet lamination and directed energy deposition. 3D fused deposition modelling (FDM), a material extrusion based technique, is the most researched technique owing to its simple, low cost and highly flexibility. FDM allows to fabricate various dosage forms with highly complex geometries that offer a great potential to customize drug release profiles. This paper reviewed systematically the technical fundamental, requirements, step by step procedure and critical parameters of a 3D FDM process.

Keywords: Three-dimension (3D) printing, 3D printed drugs, fused deposition modeling, material extrusion.

\section{I. ĐẶT VẤN ĐỀ}

In 3D là một một nền tảng công nghệ mới ứng dụng trong nhiều lĩnh vực sản xuất và công nghiệp khác nhau. Ứng dụng công nghệ in 3D trong nghiên cứu bào chế và sản xuất dược phẩm nhận được nhiều sự quan tâm trong gần một thập kỷ gần đây, đặc biệt là kể từ khi Cục quản lý thuốc và thực phẩm Mỹ (US. FDA) phê duyệt thuốc Spritam- thuốc in $3 \mathrm{D}$ đầu tiên vào năm 2015. Công nghê in 3D cho phép chế tạo ra những vât thể thật theo đúng mô hình 3 chiều được thiết kế trên máy tính với độ chính xác cao. 